\title{
Article \\ Biocomposites of Epoxidized Natural Rubber/Poly(lactic acid) Modified with Natural Fillers (Part I)
}

\author{
Anna Masek ${ }^{1, *(D)}$, Stefan Cichosz $^{1}$ and Małgorzata Piotrowska ${ }^{2}$ (D) \\ 1 Faculty of Chemistry, Institute of Polymer and Dye Technology, Lodz University of Technology, \\ Stefanowskiego 12/16, 90-924 Lodz, Poland; Stefan.cichosz@p.lodz.pl \\ 2 Faculty of Biotechnology and Food Sciences, Institute of Fermentation Technology and Microbiology, \\ Lodz University of Technology, Wolczanska 171/173, 90-924 Lodz, Poland; malgorzata.piotrowska@p.lodz.pl \\ * Correspondence: anna.masek@p.lodz.pl
}

check for updates

Citation: Masek, A.; Cichosz, S.; Piotrowska, M. Biocomposites of Epoxidized Natural Rubber/Poly(lactic acid) Modified with Natural Fillers (Part I). Int. J. Mol. Sci. 2021, 22, 3150. https:// doi.org/10.3390/ijms22063150

Academic Editor: Armando Zarrelli

Received: 18 February 2021

Accepted: 15 March 2021

Published: 19 March 2021

Publisher's Note: MDPI stays neutral with regard to jurisdictional claims in published maps and institutional affiliations.

Copyright: (c) 2021 by the authors. Licensee MDPI, Basel, Switzerland. This article is an open access article distributed under the terms and conditions of the Creative Commons Attribution (CC BY) license (https:/ / creativecommons.org/licenses/by/ $4.0 /)$.

\begin{abstract}
The study aimed to prepare sustainable and degradable elastic blends of epoxidized natural rubber (ENR) with poly(lactic acid) (PLA) that were reinforced with flax fiber (FF) and montmorillonite (MMT), simultaneously filling the gap in the literature regarding the PLA-containing polymer blends filled with natural additives. The performed study reveals that FF incorporation into ENR/PLA blend may cause a significant improvement in tensile strength from (10 \pm 1$) \mathrm{MPa}$ for the reference material to $(19 \pm 2) \mathrm{MPa}$ for the fibers-filled blend. Additionally, it was found that MMT employment in the role of the filler might contribute to ENR/PLA plasticization and considerably promote the blend elongation up to $600 \%$. This proves the successful creation of the unique and eco-friendly PLA-containing polymer blend exhibiting high elasticity. Moreover, thanks to the performed accelerated thermo-oxidative and ultraviolet (UV) aging, it was established that MMT incorporation may delay the degradation of ENR/PLA blends under the abovementioned conditions. Additionally, mold tests revealed that plant-derived fiber addition might highly enhance the ENR/PLA blend's biodeterioration potential enabling faster and more efficient growth of microorganisms. Therefore, materials presented in this research may become competitive and eco-friendly alternatives to commonly utilized petro-based polymeric products.
\end{abstract}

Keywords: cellulose; poly(lactic acid), epoxidized natural rubber; polymer blend; biodegradation

\section{Introduction}

Poly(lactic acid) (PLA) is reported to be one of the most interesting biodegradable and renewable aliphatic polyesters [1-3]. Not only is it extensively investigated and widely utilized, but PLA also exhibits a great potential to replace commonly used petrochemicalbased polymers for industrial applications, which is crucial from the environmental point of view.

In recent years, Hamad et al. [4] presented an interesting and broad review debating poly(lactic acid) blends. It covers some important and interesting aspects from PLA synthesis and large-scale production through PLA modification methods (including polymer blending) to possible applications, as well as future trends.

It is denoted that over the past years, noticeable attention has been drawn to the polymer blending technique as a way to modify PLA-based materials to obtain a product of desired properties [5-13]. Especially, rubber-incorporating blends are being intensely investigated. According to Hamad et al. [4], the first study that reported the creation of PLA/rubber blends was carried out by Ishida et al. [14].

In this work, various types of rubber were tested, e.g., nitryl-butadiene rubber (NBR), ethylene-acrylic rubber (AEM), ethylene-propylene rubber (EPM), isoprene rubber (IR) among their influence on the mechanical properties of PLA/rubber (90/10 wt\%). The results obtained from the tensile tests showed that the blends prepared with the employment of NBR and IR exhibited elevated elongations, which was explained by the absence 
of the crosslinks within the rubber structure. Additionally, the NBR-incorporating blend was reported to possess the lowest particle size $(3-4 \mu \mathrm{m})$ of the rubber domains, which, according to the research, resulted in improved impact strength. The impact strength in the case of this sample achieved a two-fold higher value compared to neat PLA.

In turn, the natural rubber (NR) amount's $(5,10,20 \mathrm{wt} \%)$ influence on the PLA/NR blend properties was studied by Bitinis et al. [15]. Scientists discovered that $10 \mathrm{wt} \% \mathrm{NR}$ resulted in the highest PLA/NR blend elongation of approximately $200 \%$. Yet, NR at 20 $\mathrm{wt} \%$ caused a drop in the tensile properties. Authors attributed this phenomenon to the possible coalescence of rubber particles that occurred at higher NR content. Consequently, it led to a considerable average particle size rise and size distribution broadening.

Another interesting research was presented by Zhang et al. [16]. The authors investigated PLA, and epoxidized natural rubber (ENR) blends with $40 \mathrm{wt} \%$ of PLA content. The specimens were prepared with the use of an internal mixer in the presence of liquid NR (LNR) that played the role of a compatibilizer between the PLA and ENR. Tensile experiments revealed a noticeable improvement in the mechanical properties when the blend contained approximately $5 \mathrm{wt} \%$ of LNR. The elongation increase in the analyzed PLA/ENR samples was noted, and the authors concluded that LNR might have acted not only as a compatibilizer but also as a plasticizing agent. Then, the plasticization was confirmed with differential scanning calorimetry (DSC) as the reference PLA sample exhibited a Tg at $62.8^{\circ} \mathrm{C}$, but when LNR was added, its value decreased to approximately $58.8^{\circ} \mathrm{C}$.

A slightly different approach to PLA properties' modification is to use the fillers of specific characteristics. Recently, natural substances are gaining significant attention [17-22] as they may contribute extensively to the creation of sustainable polymeric materials. Therefore, in the previous years, considerable interest has been given to the nature-derived additives and the effect of processing conditions on mechanical, rheological, and thermal properties of the PLA/natural filler composites [23-32].

It was shown by Barczewski et al. [33] that natural fillers may play an important role in epoxy-based polymer matrices. Additionally, Trifol et al. [34] examined nanoclay/nanocellulose PLA composites for food packaging, and Mysiukiewicz et al. [35] proved that natural substances may affect the degradation potential of PLA-based composites. Yet, even though some scientists published interesting results, less attention was drawn to PLA blend/natural additive systems. A few examples of works presenting filled PLA-based blends are presented below.

Boubekeur et al. [36] analyzed the effect of jute fibers on the properties of PLA and low-density polyethylene (LDPE) blends. The authors prepared samples consisting of 20 $\mathrm{wt} \%$ LDPE, $80 \mathrm{wt} \%$ PLA, 5 per hundred rubber (phr) compatibilizer, and fibers (0-40 phr). It was found that the incorporation of jute fibers into PLA/LDPE blends contributed to the enhancement of the thermal stability and the modulus of the blend.

Another interesting example is the work presented by Bocz et al. [37], who developed fully biodegradable blends of PLA and thermoplastic starch (TPS) filled with flax fibers. Scientists obtained a material that exhibited a synergic effect of high strength, stiffness, and thermal stability.

This research is a broadening of the works presented above. It debates the biodegradable and elastic ENR/PLA blends filled with different natural additives, which, until now, were only slightly described in the literature. The following work revealed some new aspects significant to this topic, namely, the influence of neat cellulose, flax fibers, and montmorillonite on the material properties, as well as aging of the blends, while subjected to different environmental conditions, e.g., elevated temperature, UV irradiation. Additionally, it was proven that plant-derived fibers incorporated into ENR/PLA blends might extensively enhance their biodegradation potential, enabling faster and more efficient growth of microorganisms. 


\section{Results and Discussion}

ENR/PLA blend samples were filled with commercially available cellulose (used commonly for paperboard production and paper coating), flax fibers, and montmorillonite. Plant-derived natural fibers were expected to enhance the biodegradation potential of the prepared samples and contribute to mechanical performance improvement.

According to the literature, the reinforcement could be originated from probable interactions between the hydroxyl groups in cellulosic materials and oxirane rings of ENR/ester groups of PLA $[38,39]$. The scheme of possible interactions is shown in Figure 1. The aim of using various natural fibers (neat cellulose, flax fibers) was to investigate the possibility of flax fibers (also containing lignin and hemicellulose) employment instead of neat cellulose, which derivation includes some additional processes.

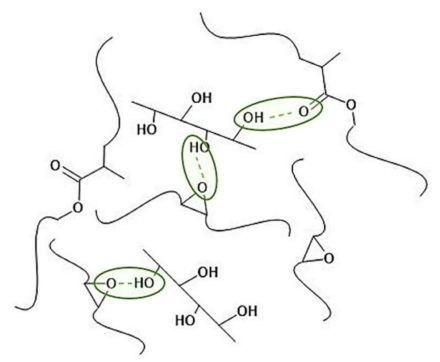

Figure 1. Examples of possible interaction in epoxidized natural rubber/poly(lactic acid) (ENR/PLA) blends between the hydroxyl group of cellulose and oxirane ring of ENR or ester group of PLA.

Additionally, montmorillonite (MMT) was employed in the role of a supplementary natural inorganic filler that could possibly affect the degradation characteristic and mechanical performance of the analyzed polymer blends.

As was mentioned above, samples prepared in this research were analyzed regarding the influence of the applied filler on the ENR/PLA blend properties and its potential impact on the specimen degradation process. Therefore, the carried-out measurements were carefully chosen. The static mechanical analysis was carried out to assess the influence of employed fillers on the performance of the prepared ENR/PLA blend specimens. Further, a swelling experiment was carried out to assess the crosslinking density as it was reported that the bonds created between different polymer macromolecules may have an influence on the mechanical properties of ENR/PLA blends and might exhibit a stabilizing effect on the properties of the material during the aging processes [40]. Moreover, it is inferred that the polymer composites of a higher polar component of surface free energy are more prone to degradation during the aging process regarding the ongoing radical reactions [41], e.g., oxidation. Therefore, the contact angle measurement, based on which the surface free energy value and its components were calculated, was carried out.

\subsection{Characterization of Specimens Before the Accelerated Ageing Process}

Regarding the data gathered in Figure 2a, it is possible to observe some variations in the swelling behaviour of prepared ENR/PLA polymer blend samples considering the filler type and employed crosslinking system. In turn, mass rise after the swelling process was proportional to the amount of solvent trapped in the structure of the analyzed specimen. The more solvent that was accommodated inside the polymer network, the lower the crosslinking degree between the polymer macromolecules. Thus, it could be concluded that natural fibers (cellulose fiber (CF), flax fiber (FF)) addition might contribute to the improvement in the density filler-polymer matrix interactions. This may be caused by both the physical interactions between hydroxyl groups of cellulosic material and oxirane rings of ENR or ester moieties of PLA (Figure 1) and covalent chemical bonds created during the vulcanization process. Thus, both physical and chemical crosslinking were present in the system described above. Moreover, lower swelling of CF- or FF-loaded specimens may also be affected by the filler's poor affinity towards the solvent herein toluene. 

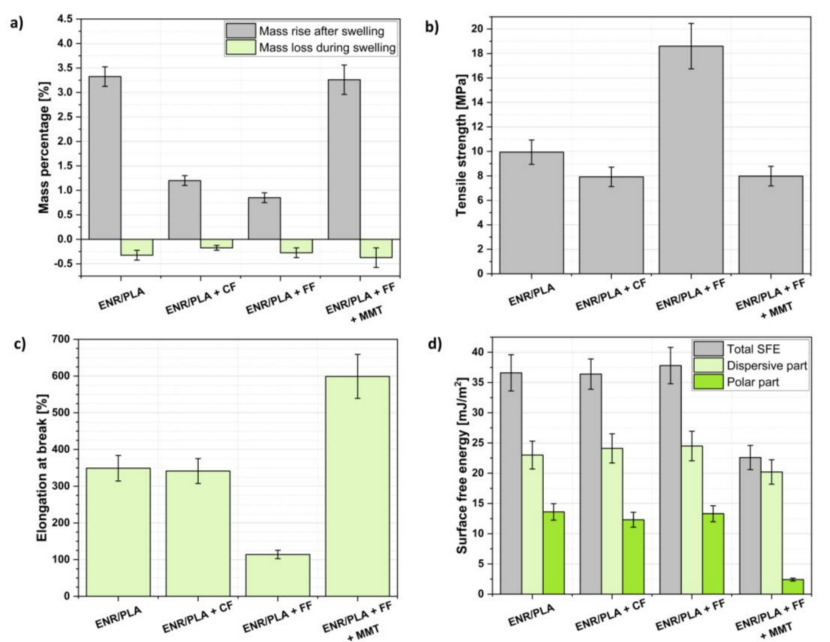

Figure 2. ENR/PLA blend properties before the accelerated aging processes: (a) analysis of the swelling experiment, (b) tensile strength of analyzed specimens, (c) elongation at break of investigated samples, (d) surface free energy, and its components analysis.

On the contrary, MMT incorporation into ENR/PLA blends caused an opposite effectthe investigated sample was swollen similarly to the neat ENR/PLA blend. This may indicate that MMT particles, which are in the shape of plates, could behave as a steric blockade and prohibit the creation of crosslinks in the structure of the polymer blend.

Moving forward, the mass loss detected during the swelling process might be attributed to some low molecular weight additives rinsed when the sample was put in the solvent environment. This could be explained by the fact that low molecular weight additives usually migrate to the surface of the polymeric material [42]. Therefore, washing out of some part of the applied additives is, in most cases, inevitable. Considering the errors accompanying the main bars (Figure 2a), the mass loss was on the same level throughout the analyzed samples, no matter what the filler was.

The highest tensile strength was evidenced in the case of the lowest swollen sample, namely ENR/PLA + FF. This results in the material stiffening and loss of the ability to elongate (Figure $2 b, c)$. An intense improvement in tensile strength of the sample filled with FF in comparison to the CF-filled ENR/PLA blend could be caused by the different structures and performances of these two fillers. Flax fibers are composed of various additional substances rich in hydroxyl moieties, e.g., lignin, hemicellulose, which may affect the polymer matrix-filler interface and intensify the predicted interactions (Figure 1). On the other hand, cellulose is a material with a homogenous chemical composition, simultaneously being capable of establishing hydrogen bonds. Despite some similarities, cellulose and flax fibers may significantly differ considering their surface characteristics, e.g., hydrophilicity, specific surface area, accessibility of surface functional groups, which may affect the filler's behavior in the polymer matrix and its effect on the properties of the polymer blend [43].

One should also consider the CF and FF behavior in the analyzed matrixes as natural fibers added to ENR/PLA blends may be concentrated only in a certain polymer domain and, thus, affect the blend properties in varied ways. According to the data gathered in the literature, cellulosic material itself may slightly contribute to the PLA tensile strength improvement-from approximately $65 \mathrm{MPa}$ to $68 \mathrm{MPa}$ (improvement of 5\%) [44]. Yet, when cellulose was added to natural rubber, an increase in tensile strength from $12 \mathrm{MPa}$ to almost $18 \mathrm{MPa}$ (improvement of 50\%) could be observed [45].

Moving forward, the sample filled with both FF and MMT exhibited lower tensile strength, which was on the level of the ENR/PLA + CF specimen. Nevertheless, the $\mathrm{ENR} / \mathrm{PLA}+\mathrm{FF}+\mathrm{MMT}$ sample revealed the highest elongation at break of approximately $600 \%$. This phenomenon could be explained with the synergic effect of MMT particles 
alignment within the structure of the polymer matrix (MMT plates are high aspect ratio particles; their orientation is a significant factor regarding the mechanical performance) and potentially lower crosslinking density (evidenced before), which leads to the material plasticization $[46,47]$. The effect of plasticization observed with MMT may be caused by free surfactant present in MMT.

A similar effect has been observed in work presented by Keawkumay et al. [48]. According to the results presented in the research, a certain MMT surface treatment may contribute to the lowering of rubber's crosslinking density and, thus, decrease the mechanical performance of a composite.

Moreover, Wang et al. [49] underlined the importance of appropriate filler dispersion within the polymer matrix. The authors presented results for MMT contents from 1-5 wt $\%$. A significant increase in the composite tensile strength was only observed in the case of low MMT contents.

On the other hand, Jiang et al. [50] drew attention to the problem of high specific surface area and shape of MMT particles—with their large L/D ratio, the MMT platelets induced lower stress concentration, which partly contributed to the higher elongation of MMT-filled blend. Similarly, scientists report that the highest values of tensile strength and elongation at break are evidenced for the MMT content up to $2.5 \mathrm{wt} \%$. This indicates that a specific aluminosilicate amount is required to ensure the most satisfying mechanical properties of a final product.

Additionally, it was proven by Papageorgiou et al. [51] and Mathew et al. [52] that natural additives, such as MMT and cellulose, might significantly influence the crystallization behavior contributing to some variations in composite mechanical properties. According to the studies, these fillers may behave as nucleating factors and promote the crystalline domain's formation. Yet, it was reported that MMT incorporation may result in the considerable imperfectness of created crystals, and, thus, it might contribute to the lowering of the stiffness and performance of a PLA-containing composite.

Confirmation for the analyzed ENR/PLA blend stiffening and plasticization can be found in Table 1, where the tensile tension values at elongation of $100 \%, 200 \%$, and $300 \%$ are presented. It is visible that the specimen filled with FF achieved the tension of (16.2 \pm $0.4) \mathrm{MPa}$ at the elongation of only $100 \%$, confirming its high stiffness. Additionally, the lowest value of tensile tension at $300 \%$ was attributed to the sample filled with both FF and MMT, which was supposed to be plasticized.

Table 1. Tensile tension at an elongation of $100 \%, 200 \%, 300 \%$ for the unfilled and filled epoxidized natural rubber/poly(lactic acid) (ENR/PLA) blend samples.

\begin{tabular}{cccc}
\hline \multirow{2}{*}{ Sample } & \multicolumn{3}{c}{ Tensile Tension [MPa] at Elongation of: } \\
\cline { 2 - 4 } & $\mathbf{1 0 0 \%}$ & $\mathbf{2 0 0 \%}$ & $\mathbf{3 0 0 \%}$ \\
\hline ENR/PLA & $4.5 \pm 0.2$ & $6.7 \pm 0.3$ & $8.8 \pm 0.2$ \\
ENR/PLA + CF & $5.9 \pm 0.2$ & $6.6 \pm 0.4$ & $7.7 \pm 0.5$ \\
ENR/PLA + FF & $16.2 \pm 0.4$ & - & - \\
ENR/PLA + FF + MMT & $5.0 \pm 0.5$ & $6.1 \pm 0.2$ & $6.6 \pm 0.3$ \\
\hline
\end{tabular}

Finally, the surface free energy (SFE) and its components are presented in Figure 2d. It may be observed that the incorporation of cellulose and flax fibers into the ENR/PLA blend did not significantly affect the surface energy characteristics. Yet, the sample filled with both FF and MMT exhibited lower total SFE and relatively slight polar component.

This phenomenon is also visible regarding the data gathered in Table 2. ENR/PLA reference blend and specimens filled with cellulose either flax fibers revealed similar water and diiodomethane droplets' behavior on the surface of the polymer blend. Nonetheless, the MMT-containing sample exhibited the contact angle for water of $(97 \pm 2)^{\circ}$ and in the case of diiodomethane- $(71 \pm 2)^{\circ}$, which were significantly higher values, when compared to the rest of the specimens. 
Table 2. Water and diiodomethane contact angles for the unfilled and filled ENR/PLA blend samples.

\begin{tabular}{ccc}
\hline \multirow{2}{*}{ Sample } & \multicolumn{2}{c}{ Contact Angle [ $\left.{ }^{\circ}\right]$} \\
\cline { 2 - 3 } & Water & Diiodomethane \\
\hline ENR/PLA & $70 \pm 3$ & $57 \pm 2$ \\
ENR/PLA + CF & $71 \pm 3$ & $56 \pm 2$ \\
ENR/PLA + FF & $69 \pm 1$ & $55 \pm 3$ \\
ENR/PLA + FF + MMT & $97 \pm 2$ & $71 \pm 2$ \\
\hline
\end{tabular}

It is often inferred that materials exhibiting a higher polar part of surface free energy (SFE) could be more affected by the aging processes [41]. Therefore, taking into consideration data gathered in Figure $2 \mathrm{~d}$ and Table 2, ENR/PLA blend filled with both FF and MMT could exhibit improved resistance to the aging processes. Yet, as FF and MMT are natural additives, the blend should still be prone to the fungi environment similar to the specimens filled only with plant-derived fibers, which exhibit a higher polar part component of surface free energy.

\subsection{Characterization of the Aging Impact}

Polymer blend samples were subjected to an accelerated aging process to assess their resistance to material degradation induced by temperature (thermo-oxidative aging) and UV light (UV irradiation; $340 \mathrm{~nm}$ ). Both aging processes indicated radical reactions, which may contribute to the oxidation, crosslinking or chain scission within the polymeric material [53]. The progress of the degradation processes was tracked via the mass control, color change, and mechanical properties variations over accelerated aging time, which was $200 \mathrm{~h}$. Time intervals between the measurements were established for $50 \mathrm{~h}$ (from 0-200 h) as the prepared samples significantly degraded during the relatively short period, $5 \mathrm{~h}$.

A summary of experiments carried out can be found in Figure 3. In general, the mass loss among the performed aging processes (Figure 3a) was higher for thermo-oxidative aging, which could be connected with the temperature-induced moisture evaporation from the natural fibers employed as fillers in the investigated polymer blends. The moisture content in plant-derived fibers is not homogenous and repetitive [54]. Therefore, the mass loss processes might be less regular among the investigated samples for thermo-oxidative aging in comparison with UV aging.

Considering Figure $3 b$, the specimens changed their visual features during both aging processes in varied ways. Thermo-oxidation caused a relatively high and quick color change in the PLA/ENR blend filled with both FF and MMT in comparison with the UV aging during which the color variations' rate was steadier. On the other hand, it could be said that UV irradiation caused more significant changes for different samples after $200 \mathrm{~h}$ of the aging process.

What should be underlined is samples of reference PLA/ENR blends became too brittle after just $100 \mathrm{~h}$ of thermo-oxidation/UV irradiation. Thus, it was impossible to carry out the color change measurements after this time as it was necessary to press the sample against the measuring instrument.

Additionally, variations of some additional parameters, such as whiteness index, chroma, and hue angle, which contribute to the final color change, are presented in Table 3. Regarding the gathered data, it might be concluded that UV aging leads to the fading of specimens resulting in less intense color visible for the human eye. Contrary, thermo-oxidative aging results in more complex and less predictable variations. 

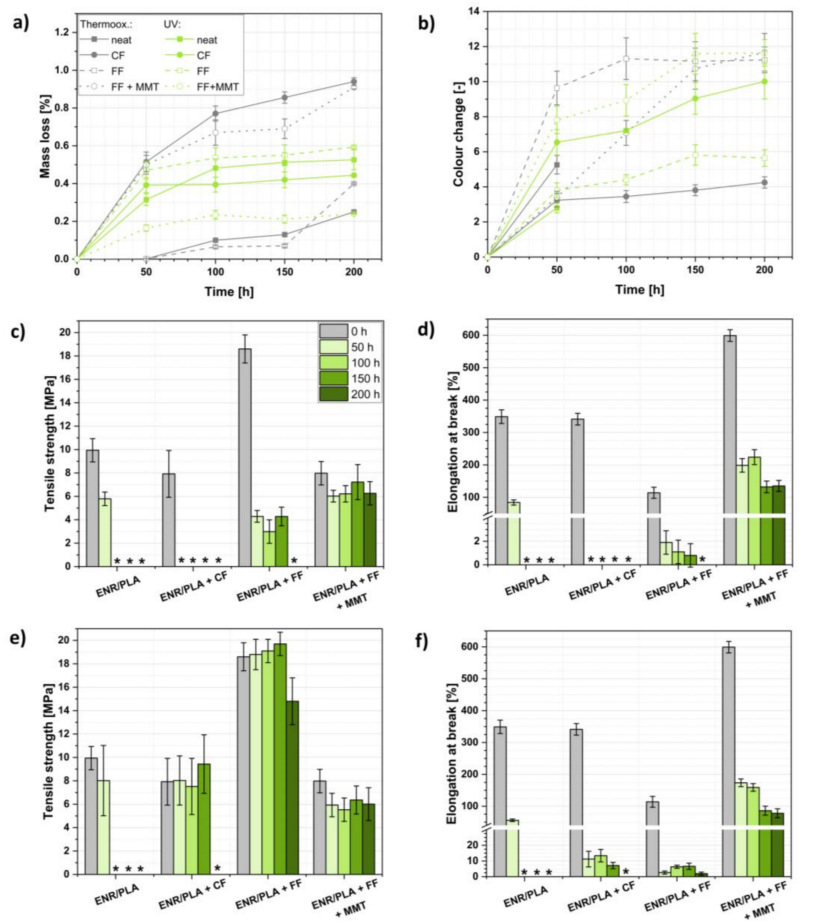

Figure 3. Investigation of the ENR/PLA blends' properties before and after the accelerated aging processes: (a) mass loss during thermo-oxidative and UV aging, (b) color change during thermooxidative and UV aging, (c) tensile strength changes and (d) elongation at break variations during thermo-oxidative aging, (e) tensile strength changes and (f) elongation at break variations during the UV aging. * sample too brittle to be examined with the selected method; the measurement was impossible.

Considering the changes in the mechanical properties of the analyzed polymer blends, it could be observed that regarding the thermo-oxidative (Figure 3c,d) and UV (Figure 3e,f) aging, samples filled with flax fibers exhibited higher resistance to the aging processes in comparison with the reference ENR/PLA blend or CF-filled ENR/PLA specimen. Moreover, as was mentioned before, prepared ENR/PLA blends seemed to be more resistant to UV irradiation, e.g., samples filled with $\mathrm{CF}$ and FF were not degrading that fast when subjected to UV aging (the tensile tests were possible to carry out; samples were flexible enough to enable the measurement).

Moving forward and comparing aging processes, it was found that UV irradiation usually caused temporary tensile strength improvement, which indicates that UV irradiation may favor the crosslinking processes, e.g., preliminary tensile strength rise for ENR/PLA + CF or ENR/PLA + FF during the UV aging. On the contrary, the increased temperature probably led to the material's intense oxidation and polymer chain scission.

As expected, the performed accelerated aging revealed the high aging resistance of the sample filled with both FF and MMT. This could be explained with the lower polar part component of the surface free energy of the analyzed specimen. Yet, barrier characteristics of MMT-filled materials and the presence of an aging-resistant inorganic fraction ought to be considered [55]. It was reported that MMT might contribute extensively to the reduction in oxygen permeability to the interior of the composite and, thus, prohibit the aging process (oxidation cannot occur) [56,57]. 
Table 3. Additional parameters contributing to the color change in ENR/PLA blends and their variations during the thermo-oxidative and UV accelerated aging processes: whiteness index, chroma, hue angle. ${ }^{*}$ sample too brittle to be examined with the selected method; the measurement was impossible.

\begin{tabular}{|c|c|c|c|c|c|}
\hline \multirow{2}{*}{ Sample } & \multicolumn{5}{|c|}{ Whiteness index Wi [-] - thermooxidation } \\
\hline & $\mathbf{O h}$ & $50 \mathrm{~h}$ & $100 \mathrm{~h}$ & $150 \mathrm{~h}$ & $200 \mathrm{~h}$ \\
\hline ENR/PLA & $40 \pm 4$ & $37 \pm 1$ & $*$ & $*$ & $*$ \\
\hline $\mathrm{ENR} / \mathrm{PLA}+\mathrm{CF}$ & $41 \pm 3$ & $38 \pm 5$ & $39 \pm 2$ & $38 \pm 3$ & $38 \pm 2$ \\
\hline ENR/PLA + FF & $41 \pm 2$ & $37 \pm 3$ & $36 \pm 2$ & $35 \pm 4$ & $39 \pm 2$ \\
\hline $\mathrm{ENR} / \mathrm{PLA}+\mathrm{FF}+\mathrm{MMT}$ & $46 \pm 2$ & $48 \pm 2$ & $41 \pm 4$ & $40 \pm 1$ & $40 \pm 3$ \\
\hline \multirow{2}{*}{ Sample } & \multicolumn{5}{|c|}{ Whiteness index Wi [-] - UV irradiation } \\
\hline & $\mathbf{O h}$ & $50 \mathrm{~h}$ & $100 \mathrm{~h}$ & $150 \mathrm{~h}$ & $200 \mathrm{~h}$ \\
\hline ENR/PLA & $40 \pm 4$ & $42 \pm 2$ & $*$ & $*$ & $*$ \\
\hline $\mathrm{ENR} / \mathrm{PLA}+\mathrm{CF}$ & $41 \pm 3$ & $40 \pm 3$ & $42 \pm 1$ & $41 \pm 2$ & $48 \pm 4$ \\
\hline ENR/PLA + FF & $41 \pm 2$ & $41 \pm 2$ & $42 \pm 2$ & $40 \pm 2$ & $42 \pm 2$ \\
\hline $\mathrm{ENR} / \mathrm{PLA}+\mathrm{FF}+\mathrm{MMT}$ & $46 \pm 2$ & $42 \pm 3$ & $41 \pm 2$ & $40 \pm 3$ & $45 \pm 2$ \\
\hline \multirow{2}{*}{ Sample } & \multicolumn{5}{|c|}{ Chroma Cab $[-]$ - thermooxidation } \\
\hline & $\mathbf{O h}$ & $50 \mathrm{~h}$ & $100 \mathrm{~h}$ & $150 \mathrm{~h}$ & $200 \mathrm{~h}$ \\
\hline ENR/PLA & $45 \pm 2$ & $50 \pm 4$ & $*$ & $*$ & $*$ \\
\hline $\mathrm{ENR} / \mathrm{PLA}+\mathrm{CF}$ & $44 \pm 2$ & $46 \pm 2$ & $44 \pm 1$ & $47 \pm 2$ & $48 \pm 4$ \\
\hline ENR/PLA + FF & $47 \pm 3$ & $45 \pm 3$ & $45 \pm 3$ & $47 \pm 2$ & $46 \pm 3$ \\
\hline $\mathrm{ENR} / \mathrm{PLA}+\mathrm{FF}+\mathrm{MMT}$ & $43 \pm 2$ & $44 \pm 1$ & $47 \pm 3$ & $42 \pm 2$ & $46 \pm 2$ \\
\hline \multirow{2}{*}{ Sample } & \multicolumn{5}{|c|}{ Chroma Cab [-] - UV irradiation } \\
\hline & $\mathbf{O h}$ & $50 \mathrm{~h}$ & $100 \mathrm{~h}$ & $150 \mathrm{~h}$ & $200 \mathrm{~h}$ \\
\hline ENR/PLA & $45 \pm 2$ & $46 \pm 2$ & $*$ & $*$ & $*$ \\
\hline $\mathrm{ENR} / \mathrm{PLA}+\mathrm{CF}$ & $44 \pm 2$ & $39 \pm 3$ & $43 \pm 2$ & $36 \pm 2$ & $36 \pm 2$ \\
\hline ENR/PLA + FF & $47 \pm 3$ & $42 \pm 2$ & $43 \pm 3$ & $40 \pm 1$ & $41 \pm 2$ \\
\hline $\mathrm{ENR} / \mathrm{PLA}+\mathrm{FF}+\mathrm{MMT}$ & $43 \pm 2$ & $43 \pm 3$ & $43 \pm 2$ & $40 \pm 3$ & $40 \pm 1$ \\
\hline \multirow{2}{*}{ Sample } & \multicolumn{5}{|c|}{ Hue angle $h_{a b}\left[{ }^{\circ}\right]-$ thermooxidation } \\
\hline & $\mathbf{O h}$ & $50 \mathrm{~h}$ & $100 \mathrm{~h}$ & $150 \mathrm{~h}$ & $200 \mathrm{~h}$ \\
\hline ENR/PLA & $83 \pm 4$ & $76 \pm 2$ & $*$ & $*$ & $*$ \\
\hline $\mathrm{ENR} / \mathrm{PLA}+\mathrm{CF}$ & $75 \pm 3$ & $73 \pm 4$ & $73 \pm 3$ & $74 \pm 4$ & $73 \pm 3$ \\
\hline ENR/PLA + FF & $81 \pm 3$ & $76 \pm 3$ & $75 \pm 2$ & $74 \pm 2$ & $77 \pm 2$ \\
\hline ENR/PLA + FF + MMT & $82 \pm 2$ & $81 \pm 2$ & $77 \pm 3$ & $73 \pm 3$ & $74 \pm 2$ \\
\hline \multirow{2}{*}{ Sample } & \multicolumn{5}{|c|}{ Hue angle hab $\left[{ }^{\circ}\right]-$ thermooxidation } \\
\hline & $\mathbf{0 ~ h}$ & $50 \mathrm{~h}$ & $100 \mathrm{~h}$ & $150 \mathrm{~h}$ & $200 \mathrm{~h}$ \\
\hline ENR/PLA & $83 \pm 4$ & $78 \pm 3$ & $*$ & $*$ & $*$ \\
\hline $\mathrm{ENR} / \mathrm{PLA}+\mathrm{CF}$ & $75 \pm 3$ & $74 \pm 3$ & $75 \pm 2$ & $74 \pm 3$ & $71 \pm 2$ \\
\hline ENR/PLA + FF & $81 \pm 3$ & $78 \pm 3$ & $79 \pm 2$ & $79 \pm 1$ & $79 \pm 2$ \\
\hline ENR/PLA + FF + MMT & $82 \pm 2$ & $77 \pm 2$ & $75 \pm 2$ & $74 \pm 3$ & $77 \pm 2$ \\
\hline
\end{tabular}

In Table 4, the aging coefficient values, calculated based on ENR/PLA blend tensile strength and elongation at break before and after the performed aging processes, are presented. The lower the $K$ value, the more degraded the material. According to the gathered data, polymer blend samples filled only with plant-derived fibers were almost fully degraded after only $50 \mathrm{~h}$ of performed accelerated aging processes. Nonetheless, the incorporation of an inorganic faction into ENR/PLA blends may successfully lead to the increased aging-resistance of the sample, e.g., when aging lasts for $200 \mathrm{~h}$ most of the samples were fully degraded, and it was impossible to carry out the measurement, but when MMT was incorporated, the measurement was possible to conduct and the blend's mechanical properties' loss was on the level of $80 \%$ ( $K$ was approximately 0.2 ). 
Table 4. Aging coefficients attributed to the filled and unfilled ENR/PLA specimens at a certain aging time. * sample too brittle to be examined with the selected method; the measurement was impossible.

\begin{tabular}{ccccc}
\hline \multirow{2}{*}{ Sample } & \multicolumn{4}{c}{ Aging coefficient K [-]-thermo-oxidation } \\
\cline { 2 - 5 } & $\mathbf{5 0} \mathbf{h}$ & $\mathbf{1 0 0} \mathbf{h}$ & $\mathbf{1 5 0} \mathbf{~}$ & $\mathbf{2 0 0} \mathbf{~}$ \\
\hline ENR/PLA & $0.14 \pm 0.06$ & $*$ & $*$ & $*$ \\
ENR/PLA + CF & $*$ & $*$ & $*$ & $*$ \\
ENR/PLA + FF & $0.004 \pm 0.002$ & $0.002 \pm 0.001$ & $0.002 \pm 0.001$ & $*$ \\
ENR/PLA + FF + MMT & $0.3 \pm 0.1$ & $0.3 \pm 0.1$ & $0.20 \pm 0,08$ & $0.20 \pm 0,07$ \\
\hline Sample & \multicolumn{4}{c}{ Ageing coefficient K [-]-UV irradiation } \\
\cline { 2 - 5 } & $\mathbf{5 0} \mathbf{h}$ & $\mathbf{1 0 0} \mathbf{h}$ & $\mathbf{1 5 0} \mathbf{~}$ & $\mathbf{2 0 0} \mathbf{~}$ \\
\hline ENR/PLA & $0.13 \pm 0.05$ & $*$ & $*$ & $*$ \\
ENR/PLA + CF & $0.03 \pm 0.01$ & $0.06 \pm 0.03$ & $0.02 \pm 0.01$ & $*$ \\
ENR/PLA + FF & $0.02 \pm 0.01$ & $0.06 \pm 0.02$ & $0.06 \pm 0.02$ & $0.01 \pm 0.01$ \\
ENR/PLA + FF + MMT & $0.2 \pm 0.1$ & $0.18 \pm 0.07$ & $0.15 \pm 0.05$ & $0.21 \pm 0.08$ \\
\hline
\end{tabular}

\subsection{Microorganism Growth Tests}

In the previous subsection, it was proved that the ENR/PLA blend degradation rate in a thermo-oxidative environment and under UV irradiation may be controlled with different natural additives, such as natural fibers or aluminosilicates. MMT incorporation contributed extensively to the improvement in the aging resistance of the investigated polymer blends.

The materials analyzed in this research were also subjected to some tests regarding the resistance of ENR/PLA blends filled with natural additives to molds. Data gathered from this experiment is presented in Table 5. It is visible that the natural fiber incorporation into the polymer matrix improved the microorganisms' growth and impaired the material ability to resist molds.

Table 5. The effect of molds on the unaged ENR/PLA blends; MGE-microorganism's growth evaluation.

\begin{tabular}{|c|c|c|c|c|c|c|}
\hline \multirow{3}{*}{ Sample } & \multicolumn{3}{|c|}{ Resistance to Moulds } & \multicolumn{3}{|c|}{ Fungistatic Effect } \\
\hline & \multicolumn{2}{|c|}{ Method A } & \multicolumn{2}{|c|}{ Method B } & \multicolumn{2}{|c|}{ Method B' } \\
\hline & MGE [-] & Picture & MGE [-] & Picture & MGE [-] & Picture \\
\hline ENR/PLA & 2 & & 4 & & 3 & \\
\hline $\begin{array}{l}\text { ENR/PLA } \\
+ \text { CF }\end{array}$ & 3 & & 5 & & 5 & \\
\hline $\begin{array}{l}\text { ENR/PLA } \\
+ \text { FF }\end{array}$ & 5 & & 4 & & 3 & \\
\hline $\begin{array}{c}\text { ENR/PLA } \\
+\mathrm{FF}+ \\
\mathrm{MMT}\end{array}$ & 5 & & 4 & & 3 & \\
\hline
\end{tabular}

Moreover, MMT presence in the ENR/PLA blend, which was the reason for the delayed material degradation when subjected to increased temperature or UV irradiation, did not affect the molds' growth on the surface of the investigated polymeric material.

According to the presented molecular growth evaluation (MGE) and information given in the standard, none of the analyzed materials was resistant to microorganism growth. Nonetheless, filling ENR/PLA blends with commercially available neat cellulose fibers and flax fibers may only increase the degradation potential of prepared materials. What is also important is inorganic silicates, which may improve the mechanical properties 
of polymer blends and contribute to the prolonged time of use in certain conditions, did not have a negative effect on the final product biodegradation.

\section{Materials and Methods}

\subsection{Materials}

The subject of the study, epoxidized natural rubber (ENR) (Epoxyprene ENR-50; 50 mol\% epoxidation), was obtained from Kumpulan Guthrie Berhad (Kuala Lumpur, Malaysia). Poly(lactic acid) (PLA) was provided by Nature Works (Minnetonka, Minnesota, USA). Cellulose fibers (CF) employed in this research were the Arbocel UFC100 Ultrafine Cellulose for Paper and Board Coating (UFC100) from J. Rettenmaier \& Soehne (Rosenberg, Germany). It was in powder form (density: $1.3 \mathrm{~g} / \mathrm{cm}^{3}$, average fiber length: $6-12 \mu \mathrm{m}, \mathrm{pH}$ : 5.0-7.5). Flax fibers (FF) employed in this research were supplied by Łukasiewicz Research Network-Institute of Biopolymers and Chemical Fibers (Lodz, Poland). Fibers were comminuted and composed of lignin, hemicellulose, and cellulose in an unknown ratio. Montmorillonite (MMT) modified nanoclay was purchased from Sigma-Aldrich (Darmstadt, Germany). It contained $25-30 \mathrm{wt} \%$ of octadecylamine grafted onto the surface. MMT particle size was approximately $20 \mu \mathrm{m}$. Lauric acid (97\% purity), 1,2-dimethylimidazole (highest available purity), obtained from Sigma-Aldrich (Darmstadt, Germany), and elastin hydrolysate, purchased from Proteina (Lodz, Poland), were used as a crosslinking system.

\subsection{Preparation of ENR/PLA Blend Samples}

Natural fibers and poly(lactic acid) were dried for $24 \mathrm{~h}$ at, respectively, $100{ }^{\circ} \mathrm{C}$ and 70 ${ }^{\circ} \mathrm{C}$ in a laboratory oven (Binder, Tuttlingen, Germany) before being incorporated into the polymer matrix. All mixture components (Table 6) were put into a micromixer (Brabender Lab-Station from Plasti-Corder with Julabo cooling system) at $160^{\circ} \mathrm{C}$ for $30 \mathrm{~min}$ (50 rpm). Next, such prepared material was placed between two roll mills with $100 \times 200 \mathrm{~mm}$ rolls, at a roll's temperature of $20-25^{\circ} \mathrm{C}$ and friction of 1:1.1 for approximately $2 \mathrm{~min}$. The last step was to compress the polymer blend plates in a hydraulic press at $160^{\circ} \mathrm{C}$ (electrically heated platens) for $60 \mathrm{~min}$ at approximately 125 bar. Therefore, the mixture was put between two steel molds and Teflon sheets.

Table 6. Composition of the polymer blend mixtures prepared for analysis in this research. Abbreviations: ENR—epoxidized natural rubber, PLA—poly(lactic acid), LA—lauric acid, DMI1,2-dimethylimidazole, EH-elastin hydrolysate, CF-cellulose fibers, FF-flax fibers, MMTmontmorillonite, phr-per hundred rubber (it means: for one hundred parts by weight of rubber there are $x$ parts by weight of the substance).

\begin{tabular}{ccccccccc}
\hline \multirow{2}{*}{ Sample } & \multicolumn{7}{c}{ Polymer Mixture Composition [phr] } \\
\cline { 2 - 9 } & ENR & PLA & LA & DMI & EH & CF & FF & MMT \\
\hline ENR/PLA & 100 & 75 & 3 & 0.6 & 0.6 & - & - & - \\
ENR/PLA + CF & 100 & 75 & 3 & 0.6 & 0.6 & 25 & - & - \\
ENR/PLA + FF & 100 & 75 & 3 & 0.6 & 0.6 & - & 25 & - \\
ENR/PLA + FF + MMT & 100 & 75 & 3 & 0.6 & 0.6 & - & 12.5 & 12.5 \\
\hline
\end{tabular}

\subsection{Accelerated Ageing of the Materials}

\subsubsection{Thermo-Oxidative Ageing}

Thermo-oxidative aging was performed in a laboratory oven (Binder, Tuttlingen, Germany) at $70{ }^{\circ} \mathrm{C}$ for $200 \mathrm{~h}$. The measurement was aimed at examining the degradation progress of the samples over time. For this purpose, 4 samples of each ENR/PLA blend were placed in an oven and were taken out individually after, respectively, $50 \mathrm{~h}, 100 \mathrm{~h}$, $150 \mathrm{~h}$, and $200 \mathrm{~h}$. 


\subsubsection{UV irradiation}

ENR/PLA blend samples were put in special metal folders and placed in the Atlas UV 2000 apparatus (Duisburg, Germany). Again, the measurement was aimed at examining the degradation progress of the samples over time. For this purpose, specimens were taken out individually after, respectively, $50 \mathrm{~h}, 100 \mathrm{~h}, 150 \mathrm{~h}$, and $200 \mathrm{~h}$. The aging cycle consisted of two alternating segments: day segment $\left(240 \mathrm{~min}, 60^{\circ} \mathrm{C}\right.$, UV irradiation: $\left.0.7 \mathrm{~W} / \mathrm{m}^{2}\right)$ and night segment $\left(120 \mathrm{~min}, 50^{\circ} \mathrm{C}\right.$, no UV radiation).

\subsection{Methods of Polymer Blend Sample Characterization}

\subsubsection{Swelling in Toluene}

The principle of the measurement was based on measuring the weight gain of the sample that was subjected to the organic solvent environment (toluene). From each vulcanizate, 4 samples of different shapes were cut out (the weight of each ranged from 30 to $40 \mathrm{mg})$. The samples were weighed before the measurement $\left(\mathrm{m}_{1}\right)$ and then immersed in a solvent. After $48 \mathrm{~h}$, they were taken out and weighed again $\left(\mathrm{m}_{2}\right)$. Before weighing the wet sample, the excess toluene was cleaned with filter paper, and then the sample was immersed in ethyl ether for 1-2 s. The samples were dried to constant weight in an oven at $50{ }^{\circ} \mathrm{C}$ for $96 \mathrm{~h}$ and weighed again $\left(\mathrm{m}_{3}\right)$. To analyze the potential crosslinking density, two parameters were calculated: $\mathrm{m}_{\text {rise }}=\mathrm{m}_{2}-\mathrm{m}_{1}\left(\mathrm{~m}_{\text {rise }}\right.$ reveals how much the sample is swollen in the solvent), $\mathrm{m}_{\text {loss }}=\mathrm{m}_{3}-\mathrm{m}_{1}$ ( $\mathrm{m}_{\text {loss }}$ informs about the low molecular weight compounds washed out during the swelling in toluene).

\subsubsection{Contact Angle Measurement}

Surface free energy was determined based on contact angle measurements done for two liquids: distilled water, diiodomethane (droplet volume of $1 \mu \mathrm{L}$ ). Before the measurement, the blend's surface was cleaned with acetone. An OCA 15EC goniometer by DataPhysics Instruments $\mathrm{GmbH}$ (Filderstadt, Germany) equipped with a single direct dosing system (0.01-1 $\mathrm{mL}$ B. Braun syringe, Hassen, Germany) was employed, and the surface free energy was calculated thanks to the Owens-Wendt-Rabel-Kaelble (OWRK) method.

\subsubsection{Tensile Tests}

Mechanical properties, such as tensile strength (TS) and elongation at break (Eb), were determined with the use of a Zwick-Roell 1435 measuring device (Ulm, Germany). Tests were carried out on a "dumbbell" shape, approximately $1.5 \mathrm{~mm}$ thick and $4 \mathrm{~mm}$ width specimens, according to PN-ISO 37:1998 standard. Specimens were cut out with the use of a punch described in the standard. Based on the obtained results, the aging coefficient $K$ was calculated as a quotient of the product of TS and $\mathrm{Eb}$ after and before the performed aging process [58].

\subsubsection{Color Change}

Optical properties' characterization was determined with a Spectrophotometer UV-VIS CM-36001 from Konica Minolta. Sample color was described with the CIE-Lab system ( $L-$ lightness, $a$-red-green, $b$-yellow-blue). Then, according to the equations given below (1-4), color difference $(\Delta E)$, whiteness index $\left(W_{i}\right)$, chroma $\left(C_{a b}\right)$, and hue angle $\left(h_{a b}\right)$ values were calculated. $\Delta a, \Delta b, \Delta L$ were the coordinate differences between aged and unaged samples:

$$
\begin{gathered}
\Delta E=\sqrt{(\Delta a)^{2}+(\Delta b)^{2}+(\Delta L)^{2}} \\
W_{i}=100-\sqrt{a^{2}+b^{2}+(100-L)^{2}} \\
C_{a b}=\sqrt{a^{2}+b^{2}}
\end{gathered}
$$




$$
h_{a b}=\left\{\begin{array}{c}
\operatorname{arctg}\left(\frac{b}{a}\right), \text { when } a>0 \wedge b>0 \\
180^{\circ}+\operatorname{arctg}\left(\frac{b}{a}\right), \text { when }(a<0 \wedge b>0) \vee(a<0 \wedge b<0) \\
360^{\circ}+\operatorname{arctg}\left(\frac{b}{a}\right), \text { when } a>0 \wedge b<0
\end{array}\right.
$$

\subsubsection{Mass Loss during the Degradation Process}

Before and during the accelerated aging process, specially prepared samples were weighed at the following times: $0 \mathrm{~h}, 50 \mathrm{~h}, 100 \mathrm{~h}, 150 \mathrm{~h}$, and $200 \mathrm{~h}$. The experiment aimed to show how the mass of the specimens subjected to accelerated aging changed during the degradation.

\subsection{Microorganism Growth Tests}

The effect of molds on the materials tested was assessed in accordance with ISO 846. A mixed suspension in salt solutions of Aspergillus niger, Paecilomyces variotii, Chaetomium globosum, Trichoderma viride, and Penicillium funiculosum strains was used as a test organism. In tests, two microbial media were used: (1) incomplete nutrient solution medium $\left(\mathrm{NaNO}_{3} 2.0 \mathrm{~g}\right.$; $\mathrm{KH}_{2} \mathrm{PO}_{4} 0.7 \mathrm{~g} ; \mathrm{K}_{2} \mathrm{HPO}_{4} 0.3 \mathrm{~g}$; $\mathrm{KCl} 0.5 \mathrm{~g} ; \mathrm{MgSO}_{4} 7 \mathrm{H}_{2} \mathrm{O} 0.01 \mathrm{~g}$, agar $20 \mathrm{~g}$; water $1000 \mathrm{~mL}$, pH 6.0-6.5) for method $\mathrm{A}$, and (2) complete nutrient medium with the composition as above with $30 \mathrm{~g}$ of glucose for method $\mathrm{B}$ and variant $\mathrm{B}^{\prime}$.

In method $A$, the natural resistance of the material when no other nutrient substance was present was tested. The material was disinfected with $75 \%$ ethanol and then placed on medium (1), and a suspension of molds was added (batch I). Simultaneously, batch S was prepared without microorganisms as a control.

In method B, the fungistatic effect and the influence of surface contamination on the resistance of the material were tested. Material samples without disinfection were placed on medium (2), followed by a uniform deposition of the microorganism suspension. In method B', first, the mold suspension was plated on the medium, and after 5 days of incubation at $25^{\circ} \mathrm{C}$, the test material was placed on a plate surface.

The samples were incubated at $28{ }^{\circ} \mathrm{C}$ and relative humidity (RH) $80 \%$ for 5 weeks (Climatic Chamber BINDER).

Afterward, the intensity of growth of microorganisms on both the nutrient media and samples was observed and evaluated using an assessment scale from 0 to 5 in accordance with ISO 846: no visible growth under the microscope (0); visible under a microscope (1); growth covering up to $25 \%$ of the sample area (2); growth covering up to $50 \%$ of the sample area (3); significant growth, covering more than $50 \%$ of the sample area (4); intensive growth covering the entire surface of the sample (5).

The final interpretation was for method A: 0 - the material is not a breeding ground for microorganisms; 1 -the material contains nutrients or is slightly contaminated to allow slight growth; 2-5-the material is not resistant to the action of microorganisms and contains substances that support their growth. For method B/B': 0 - strong fungistatic effect; 1-5-lack of fungistatic effect.

\section{Conclusions}

Concluding, the elastic blends of epoxidized natural rubber (ENR) with poly(lactic acid) (PLA) were successfully created. Regarding the fact that they were reinforced with flax fiber (FF) and montmorillonite (MMT), some additional functional properties were introduced, e.g., improved biodegradation potential, improved mechanical performance/elongation.

Thanks to the research carried out, it was shown that FF incorporation into ENR/PLA blend caused a significant improvement in tensile strength up to (19 \pm 2$) \mathrm{MPa}$, simultaneously contributing to the loss of an ability of a polymer blend to elongate (material stiffening). On the contrary, MMT employment in the role of the filler led to ENR/PLA blend plasticization and enabled the polymer blend's elongation on the level of approx- 
imately $600 \%$. Nevertheless, MMT-filled material exhibited significantly lower tensile strength in comparison with the samples filled with only plant-derived fibers.

Moreover, based on the gathered results, it can be concluded that the composite samples subjected to elevated temperature and UV irradiation underwent some notable changes in their properties. It was established that MMT incorporation delayed the degradation of the ENR/PLA elastic blends under the abovementioned conditions without affecting their biodeterioration potential. Thanks to the mold tests carried out, it was proven that plant-derived fibers incorporated into ENR/PLA blends significantly enhanced their biodegradation potential, enabling faster and more efficient growth of the microorganisms. Importantly, the biodeterioration ability was not affected by the MMT incorporation.

Significantly, it should be mentioned that, in comparison with literature data, ENR/PLA blends prepared in this research not only did exhibit improved degradation potential but were also characterized by a performance higher than noted for neat ENR vulcanizates. According to the article by Intharapat et al. [59], unfilled ENR products reveal a tensile strength of approximately $2 \mathrm{MPa}$. Additionally, when ENR is filled with rice husk ash, the vulcanizate's performance might be elevated up to $16 \mathrm{MPa}$ [60], which is lower than the tensile strength of FF-filled ENR/PLA blend (approximately $19 \mathrm{MPa}$ ). Obviously, the ENR/PLA blends' ability to elongate was limited by the PLA content, and, thus, the elongation at break of neat ENR vulcanizates was usually higher.

Gathering the presented information, it can be stated that biodegradable and elastic ENR/PLA blends are good materials for producing consumer products characterized by a short or long lifespan depending on the organic-inorganic phase ratio, which can be controlled by the amounts of different natural additives. Furthermore, the pro-ecological character of the produced polymer blends and their mechanical performance make them competitive and enable their widespread application in various branches of industry, while meeting current ecological requirements.

Author Contributions: Conceptualization, formal analysis, data analysis, investigation, methodology, review and editing, A.M.; data analysis, methodology, and writing, S.C.; microbiological tests and description of results, methodology, M.P. All authors have read and agreed to the published version of the manuscript.

Funding: No external funding was provided.

Institutional Review Board Statement: Not applicable.

Informed Consent Statement: Not applicable.

Data Availability Statement: No data available.

Acknowledgments: This work has been completed while the second author was the Doctoral Candidate in the Interdisciplinary Doctoral School at the Lodz University of Technology, Poland.

Conflicts of Interest: The authors declare no conflict of interest.

\section{References}

1. Farah, S.; Anderson, D.G.; Langer, R. Physical and mechanical properties of PLA, and their functions in widespread applicationsA comprehensive review. Adv. Drug Deliv. Rev. 2016, 107, 367-392. [CrossRef]

2. Rayung, M.; Ibrahim, N.A.; Zainuddin, N.; Saad, W.Z.; Razak, N.I.A.; Chieng, B.W. The Effect of Fiber Bleaching Treatment on the Properties of Poly(lactic acid)/Oil Palm Empty Fruit Bunch Fiber Composites. Int. J. Mol. Sci. 2014, 15, 14728-14742. [CrossRef] [PubMed]

3. Aliotta, L.; Gigante, V.; Coltelli, M.B.; Cinelli, P.; Lazzeri, A. Evaluation of Mechanical and Interfacial Properties of Bio-Composites Based on Poly(Lactic Acid) with Natural Cellulose Fibers. Int. J. Mol. Sci. 2019, 20, 960. [CrossRef] [PubMed]

4. Hamad, K.; Kaseem, M.; Ayyoob, M.; Joo, J.; Deri, F. Polylactic acid blends: The future of green, light and tough. Prog. Polym. Sci. 2018, 85, 83-127. [CrossRef]

5. Müller, P.; Bere, J.; Fekete, E.; Móczó, J.; Nagy, B.; Kállay, M.; Gyarmati, B.; Pukánszky, B. Interactions, structure and properties in PLA/plasticized starch blends. Polymer 2016, 103, 9-18. [CrossRef]

6. Bijarimi, M.; Ahmad, S.; Rasid, R. Mechanical, thermal and morphological properties of poly(lactic acid)/epoxidized natural rubber blends. J. Elastomers Plast. 2012, 46, 338-354. [CrossRef] 
7. Andrzejewski, J.; Skórczewska, K.; Kloziński, A. Improving the toughness and thermal resistance of polyoxymeth-ylene/poly(lactic acid) blends: Evaluation of structure-properties correlation for reactive processing. Polymers 2020, 12, 307. [CrossRef] [PubMed]

8. Formela, K.; Zedler, Ł.; Hejna, A.; Tercjak, A. Reactive extrusion of bio-based polymer blends and composites-current trends and future developments. Express Polym. Lett. 2018, 12, 24-57. [CrossRef]

9. Yao, Q.; Cosme, J.G.; Xu, T.; Miszuk, J.M.; Picciani, P.H.; Fong, H.; Sun, H. Three dimensional electrospun PCL/PLA blend nanofibrous scaffolds with significantly improved stem cells osteogenic differentiation and cranial bone formation. Biomaterials 2017, 115, 115-127. [CrossRef]

10. Ahmed, M.F.; Li, Y.; Yao, Z.; Cao, K.; Zeng, C. TPU/PLA blend foams: Enhanced foamability, structural stability, and implications for shape memory foams. J. Appl. Polym. Sci. 2019, 136, 1-12. [CrossRef]

11. Siracusa, V.; Karpova, S.; Olkhov, A.; Zhulkina, A.; Kosenko, R.; Iordanskii, A. Gas Transport Phenomena and Polymer Dynamics in PHB/PLA Blend Films as Potential Packaging Materials. Polymers 2020, 12, 647. [CrossRef] [PubMed]

12. Kwiecien, I.; Adamus, G.; Jiang, G.; Radecka, I.; Baldwin, T.C.; Khan, H.R.; Johnston, B.; Pennetta, V.; Hill, D.; Bretz, I.; et al. Biodegradable PBAT/PLA Blend with Bioactive MCPA-PHBV Conjugate Suppresses Weed Growth. Biomacromolecules 2018, 19, 511-520. [CrossRef]

13. Sookprasert, P.; Hinchiranan, N. Morphology, mechanical and thermal properties of poly(lactic acid) (PLA)/natural rubber (NR) blends compatibilized by NR-graft-PLA. J. Mater. Res. 2017, 32, 788-800. [CrossRef]

14. Ishida, S.; Nagasaki, R.; Chino, K.; Dong, T.; Inoue, Y. Toughening of poly(L-lactide) by melt blending with rubbers. J. Appl. Polym. Sci. 2009, 113, 558-566. [CrossRef]

15. Bitinis, N.; Verdejo, R.; Cassagnau, P.; Lopez-Manchado, M. Structure and properties of polylactide/natural rubber blends. Mater. Chem. Phys. 2011, 129, 823-831. [CrossRef]

16. Zhang, C.; Wang, W.; Huang, Y.; Pan, Y.; Jiang, L.; Dan, Y.; Luo, Y.; Peng, Z. Thermal, mechanical and rheological properties of polylactide toughened by expoxidized natural rubber. Mater. Des. 2013, 45, 198-205. [CrossRef]

17. Członka, S.; Strakkowska, A. Rigid Polyurethane Foams Based on BioPolyol and Additionally Reinforced with Silanized and Acetylated Walnut Shells for the Synthesis of Environmentally Friendly Insulating Materials. Materials 2020, 13, 3245. [CrossRef]

18. Członka, S.; Kairyte, A.; Miedzinska, K.; Strakowska, A. Polyurethane Hybrid Composites Reinforced with Lavender Residue Functionalized with Kaolinite and Hydroxyapatite. Materials 2021, 14, 415. [CrossRef] [PubMed]

19. Kairyte, A.; Kremensas, A.; Vaitkus, S.; Członka, S.; Strakowska, A. Fire suppression and thermal behavior of biobased rigid polyurethane foam filled with biomass incinerationwaste ash. Polymers 2020, 12, 683. [CrossRef]

20. Bartos, A.; Anggono, J.; Farkas, Á.E.; Kun, D.; Soetaredjo, F.E.; Móczó, J.; Purwaningsih, H.; Pukánszky, B. Alkali treatment of lignocellulosic fibers extracted from sugarcane bagasse: Composition, structure, properties. Polym. Test. 2020, 88, 106549. [CrossRef]

21. Szadkowski, B.; Kuśmierek, M.; Rybiński, P.; Zukowski, W.; Marzec, A. Application of earth pigments in cycloolefin co-polymer: Protection against combustion and accelerated aging in the full sunlight spectrum. Materials 2020, 13, 3381. [CrossRef]

22. Blessing, B.; Trout, C.; Morales, A.; Rybacki, K.; Love, S.A.; Lamoureux, G.; O’Malley, S.M.; Hu, X.; la Cruz, D.S.-D. The Impact of Composition and Morphology on Ionic Conductivity of Silk/Cellulose Bio-Composites Fabricated from Ionic Liquid and Varying Percentages of Coagulation Agents. Int. J. Mol. Sci. 2020, 21, 4695. [CrossRef]

23. Porras, A.; Maranon, A. Development and characterization of a laminate composite material from polylactic acid (PLA) and woven bamboo fabric. Compos. Part B Eng. 2012, 43, 2782-2788. [CrossRef]

24. Bajpai, P.K.; Singh, I.; Madaan, J. Development and characterization of PLA-based green composites: A review. J. Thermo-Plast. Compos. Mater. 2014, 27, 52-81. [CrossRef]

25. Dong, Y.; Ghataura, A.; Takagi, H.; Haroosh, H.J.; Nakagaito, A.N.; Lau, K.-T. Polylactic acid (PLA) biocomposites reinforced with coir fibres: Evaluation of mechanical performance and multifunctional properties. Compos. Part A Appl. Sci. Manuf. 2014, 63, 76-84. [CrossRef]

26. Shumao, L.; Jie, R.; Hua, Y.; Tao, Y.; Weizhong, Y. Influence of ammonium polyphosphate on the flame retardancy andmechanical properties of ramie fiber-reinforced poly(lactic acid) biocomposites. Polym. Int. 2010, 59, 242-248. [CrossRef]

27. Plackett, D.; Andersen, T.L.; Pedersen, W.B.; Nielsen, L. Biodegradable composites based on l-polylactide and jute fibres. Compos. Sci. Technol. 2003, 63, 1287-1296. [CrossRef]

28. Csikós, Á.; Faludi, G.; Domján, A.; Renner, K.; Móczó, J.; Pukánszky, B. Modification of interfacial adhesion with a functionalized polymer in PLA/wood composites. Eur. Polym. J. 2015, 68, 592-600. [CrossRef]

29. Hegyesi, N.; Zhang, Y.; Kohári, A.; Polyák, P.; Sui, X.; Pukánszky, B. Enzymatic degradation of PLA/cellulose nanocrystal composites. Ind. Crop. Prod. 2019, 141, 111799. [CrossRef]

30. Csizmadia, R.; Faludi, G.; Renner, K.; Moczo, J.; Pukanszky, B. PLA/wood biocomposites: Improving composite strength by chemical treatment of the fibers. Compos. Part A Appl. Sci. Manuf. 2013, 53, 46-53. [CrossRef]

31. Andrzejewski, J.; Szostak, M.; Barczewski, M.; Łuczak, P. Cork-wood hybrid filler system for polypropylene and poly(lactic acid) based injection molded composites. Structure evaluation and mechanical performance. Compos. Part B Eng. 2019, 163, 655-668. [CrossRef]

32. Barczewski, M.; Mysiukiewicz, O.; Matykiewicz, D.; Skórczewska, K.; Lewandowski, K.; Andrzejewski, J.; Piasecki, A. Development of polylactide composites with improved thermomechanical properties by simultaneous use of basalt powder and a nucleating agent. Polym. Compos. 2020, 41, 2947-2957. [CrossRef] 
33. Barczewski, M.; Sałasińska, K.; Szulc, J. Application of sunflower husk, hazelnut shell and walnut shell as waste agricultural fillers for epoxy-based composites: A study into mechanical behavior related to structural and rheological properties. Polym. Test. 2019, 75, 1-11. [CrossRef]

34. Trifol, J.; Plackett, D.; Sillard, C.; Szabo, P.; Bras, J.; Daugaard, A.E. Hybrid poly(lactic acid)/nanocellulose/nanoclay composites with synergistically enhanced barrier properties and improved thermomechanical resistance. Polym. Int. 2016, 65, 988-995. [CrossRef]

35. Mysiukiewicz, O.; Barczewski, M.; Skórczewska, K.; Szulc, J.; Kloziński, A. Accelerated Weathering of Polylactide-Based Composites Filled with Linseed Cake: The Influence of Time and Oil Content within the Filler. Polymers 2019, 11, 1495. [CrossRef]

36. Boubekeur, B.; Belhaneche-Bensemra, N.; Massardier, V. Valorization of waste jute fibers in developing low-density polyethylene /poly lactic acid bio-based composites. J. Reinf. Plast. Compos. 2015, 34, 649-661. [CrossRef]

37. Bocz, K.; Szolnoki, B.; Marosi, A.; Tábi, T.; Wladyka-Przybylak, M.; Marosi, G. Flax fibre reinforced PLA/TPS biocomposites flame retarded with multifunctional additive system. Polym. Degrad. Stab. 2014, 106, 63-73. [CrossRef]

38. Xu, C.; Zheng, Z.; Wu, W.; Fu, L.; Lin, B. Design of healable epoxy composite based on $\beta$-hydroxyl esters crosslinked networks by using carboxylated cellulose nanocrystals as crosslinker. Compos. Sci. Technol. 2019, 181, 107677. [CrossRef]

39. Harani, H.; Fellahi, S.; Bakar, M. Toughening of epoxy resin using hydroxyl-terminated polyesters. J. Appl. Polym. Sci. 1999, 71, 29-38. [CrossRef]

40. Liu, H.; Fang, Z.; Peng, M.; Shen, L.; Wang, Y. The effects of irradiation cross-linking on the thermal degradation and flameretardant properties of the HDPE/EVA/magnesium hydroxide composites. Radiat. Phys. Chem. 2009, 78, 922-926. [CrossRef]

41. Żołek-Tryznowska, Z.; Prica, M.; Pavlović, Ž.; Cveticanin, L.; Annusik, T. The influence of aging on surface free energy of corona treated packaging films. Polym. Test. 2020, 89, 106629. [CrossRef]

42. Homma, H.; Kuroyagi, T.; Mirley, C.L.; Ronzello, J.; Boggs, S.A. Diffusion of low molecular weight siloxane from bulk to surface [outdoor insulators]. In Proceedings of the 1996 IEEE International Symposium on Electrical Insulation, Montreal, QC, Canada, 16-19 June 1996; pp. 279-282.

43. Bismarck, A.; Aranberri-Askargorta, I.; Lampke, T.; Wielage, B.; Stamboulis, A.; Shenderovich, I.; Limbach, H.-H. Surface characterization of flax, hemp and cellulose fibers; Surface properties and the water uptake behavior. Polym. Compos. 2002, 23, 872-894. [CrossRef]

44. Awal, A.; Rana, M.; Sain, M. Thermorheological and mechanical properties of cellulose reinforced PLA bio-composites. Mech. Mater. 2015, 80, 87-95. [CrossRef]

45. Roy, K.; Debnath, S.C.; Pongwisuthiruchte, A.; Potiyaraj, P. Natural Rubber/Microcrystalline Cellulose Composites with Epoxidized Natural Rubber as Compatibilizer. Rubber Chem. Technol. 2019, 92, 378-387. [CrossRef]

46. Selvakumar, V.; Palanikumar, K.; Palanivelu, K. Studies on Mechanical Characterization of Polypropylene/Na-MMT Nanocomposites. J. Miner. Mater. Charact. Eng. 2010, 9, 671-681. [CrossRef]

47. Bee, S.-T.; Abdullah, M.; Sin, L.T.; Rahmat, A. Polymer nanocomposites based on silylated-montmorillonite: A review. Prog. Polym. Sci. 2018, 85, 57-82. [CrossRef]

48. Keawkumay, C.; Jarukumjorn, K.; Wittayakun, J.; Suppakarn, N. Influences of surfactant content and type on physical properties of natural rubber/organoclay nanocomposites. J. Polym. Res. 2012, 19, 19. [CrossRef]

49. Wang, Y.; Gao, J.; Ma, Y.; Agarwal, U.S. Study on mechanical properties, thermal stability and crystallization behavior of PET/MMT nanocomposites. Compos. Part B Eng. 2006, 37, 399-407. [CrossRef]

50. Jiang, L.; Zhang, J.; Wolcott, M.P. Comparison of polylactide/nano-sized calcium carbonate and polylactide/montmorillonite composites: Reinforcing effects and toughening mechanisms. Polymers 2007, 48, 7632-7644. [CrossRef]

51. Papageorgiou, G.; Achilias, D.; Nanaki, S.; Beslikas, T.; Bikiaris, D. PLA nanocomposites: Effect of filler type on non-isothermal crystallization. Thermochim. Acta 2010, 511, 129-139. [CrossRef]

52. Mathew, A.P.; Oksman, K.; Sain, M. The effect of morphology and chemical characteristics of cellulose reinforcements on the crystallinity of polylactic acid. J. Appl. Polym. Sci. 2006, 101, 300-310. [CrossRef]

53. Seguchi, T.; Tamura, K.; Shimada, A.; Sugimoto, M.; Kudoh, H. Mechanism of antioxidant interaction on polymer oxidation by thermal and radiation ageing. Radiat. Phys. Chem. 2012, 81, 1747-1751. [CrossRef]

54. Sun, C.C. Mechanism of moisture induced variations in true density and compaction properties of microcrystalline cellulose. Int. J. Pharm. 2008, 346, 93-101. [CrossRef] [PubMed]

55. Oleyaei, S.A.; Almasi, H.; Ghanbarzadeh, B.; Moayedi, A.A. Synergistic reinforcing effect of TiO 2 and montmorillonite on potato starch nanocomposite films: Thermal, mechanical and barrier properties. Carbohydr. Polym. 2016, 152, 253-262. [CrossRef]

56. Ramesh, P.; Prasad, B.D.; Narayana, K.L. Effect of MMT Clay on Mechanical, Thermal and Barrier Properties of Treated Aloevera Fiber/ PLA-Hybrid Biocomposites. Silicon 2020, 12, 1751-1760. [CrossRef]

57. Othman, S.H.; Ling, H.N.; Talib, R.A.; Naim, M.N.; Risyon, N.P. Saifullah PLA/MMT and PLA/Halloysite Bio-Nanocomposite Films: Mechanical, Barrier, and Transparency. J. Nano Res. 2019, 59, 77-93. [CrossRef]

58. Marzec, A.; Szadkowski, B.; Kuśmierek, M.; Rogowski, J.; Maniukiewicz, W.; Rybiński, P.; Zaborski, M. Impact of organicinorganic color additive on the properties of ethylene-norbornene copolymer. Polym. Test. 2020, 82, 106290. [CrossRef]

59. Intharapat, P.; Kongnoo, A.; Kateungngan, K. The Potential of Chicken Eggshell Waste as a Bio-filler Filled Epoxidized Natural Rubber (ENR) Composite and its Properties. J. Polym. Environ. 2013, 21, 245-258. [CrossRef]

60. Pongdong, W.; Nakason, C.; Kummerlöwe, C.; Vennemann, N. Influence of filler from a renewable resource and silane coupling agent on the properties of epoxidized natural rubber vulcanizates. J. Chem. 2015, 2015. [CrossRef] 